\title{
Visual Media as a Means of Psychological Therapy
}

\author{
Sayid Mataram ${ }^{1}$ and Deny Tri Ardianto ${ }^{2}$ \\ ${ }^{1,2}$ Faculty of Arts and Design, UniversitasSebelasMaret, Surakarta, Indonesia \\ ${ }^{1}$ sayidmataram@staff.uns.ac.id ,2denytri@staff.uns.ac.id
}

\begin{abstract}
There are many cases of psychological disorders and one of the causes isthe sufferers' high levels of stress. Fine art can be utilized as a therapeutic medium for psychological disorders by using media displayed either visually or audio-visually. This research was a qualitative phenomenological research that applied descriptive methods to review the role and variety of visual media in dealing with psychological problems. The range of visual media studied included illustrations, comics, films and interactive animation. The use of visual media results in benefits that improve resilience in people with psychological disorders. Resilience is an effort to relieve stress and harmonize the mind which will bring out the latent capacity of psychological disorder sufferers to overcome their psychological trauma and protect them from their mental disorders.
\end{abstract}

Keywords: media visual, resilience, traumatic healing therapies, psychology

\section{INTRODUCTION}

Humans are created to have feelings that respond to states of happiness, sadness, fear, anger, and so on. Human feelings arise because of the action-reaction to certain conditions. The different feelings that arise will leave different scars. When someone feels pleasure, he might show the expression of happiness by laughing so hard that excitement seems to blanket him. But if the condition that occurs is a negative one such as sadness, the people who experience it will feel hurt, which of course the pain is not physical. When someone experiences a negative event which then leads to an abnormal condition both psychologically and behaviorally, it can be said that the person is experiencing stress which can result in psychological trauma. Psychological trauma is a state of mind or abnormal behavior as a result of mental stress or physical injury [1].

The American Psychiatric Association (APA) created a manual that provides a system for classifying psychological disorders, namely the Diagnostic and Statistical Manual of Mental Disorder (DSM). One type of psychological disorder is Post-traumatic Stress Disorder (PTSD). PTSD may follow utomobile accidents, assaults, abuse, and the experience of natural disasters. PTSD symptoms include hypervigilance; avoidance of stimuli associated with the trauma; emotional numbing; and repetitive, intrusive thoughts, flashbacks, and dreams about the traumatic event [2]. PTSD is a survival reaction. Symptoms arise from the intention to defend themselves from further traumatic experiences that include increased levels of stress hormones and other changes in the brain [3]. People with psychological problems will be haunted by a memory of a very painful past event that they have experienced.

The world of psychology recognizes several healing techniques or therapies for people with psychiatric disorders. The types of therapies carried out for sufferers are categorized according to the philosophy on which they are based. These types of therapy include psychoanalytical and 
psychodynamic, cognitive and behavioral, humanistic, systemic, role of medicine [3]. In addition to the therapeutic steps that require help from others, humans also have a psychological defense response system, namely repression, denial, regression, projection, rationalization, reaction formation, and shift [4].

Current technological developments have resulted in a variety of visual media, including audio-visual media. The media is a series of devices intended to provide a visual presentation that contains messages or is used for certain purposes. Some examples of visual media are in the forms of films, animation, and comics. Over time, these media are often created to repeat and reconstruct or create a pseudo design of a condition. McCloud, with his capacity in the comics field, argued that in the comics, there are various messages to be conveyed to the readers who are containedtechnically in the images and or narration [5].

The purpose of this study is to explain that there are media related to the world of visual communication that can be used as a medium of PTSD therapy in the world of psychology. In addition, this study describes cases of visual media involvement in the therapeutic effort.

\section{METHOD}

This research is a descriptive qualitative research using case study approach. The case study approach is a type of qualitative research in which the researcher explores a single entity or a phenomenon that is bound by time and activity then collects information in detail within a certain period of time [6]. The case study in this research is related to visual media, including audio visual media, which contains content or is used as psychological trauma healing therapy. The sources of data used include 1) informants (psychologists), 2) events related to media use, and 3) documents that discuss cases that are relevant to psychology and visual media as healing therapies.

To determine the relevance of visual media content to psychological therapeutic measures, content analysis approach was used. Content analysis is a research technique for making replicable and valid inferences from texts (or other meaningful matters) to the contexts of their use [7]. Visual media have a large variety of objects presented, taking this into account, it is necessary to observe the content or substance of these presentations. Therefore, this research will focus more on the narrative side of the media than the types of media in use.

\section{RESULT AND DISCUSSION}

The media today haveundergone dramatic development. These developments then gave rise to the terms conventional media and new media. The existing new media is not merely limited to the digitalization of conventional media. There are grounds for classifying media as new media which, of course, are not absolute but a general tendency of numerical representation, modularity, automation, variability, and transcoding [8].

Apart from the dichotomy of conventional and new media, there are various lines of media including visual media, audio media, and audio visual media. Audio media presents images in the form of sound, and visual media presents images that can be captured with the sense of sight, while audio visual media presents images that are captured with the colaboration of hearing and vision senses.

In the world of psychology, these media are often used as a therapeutic tool such as classical music with its distinctive rhythm, soothing music, images as symbols that imply specific intentions, visual interaction media to stimulate thought processes, and so on.

Psychological disorders often impact on ways of thinking which then lead to unnatural behaviours or not in accordance with the common states, either more or less than the normal human behaviors. Thus, a media that can stimulate cognitive abilities or the ability to think rationally is needed. According to Mayer, there are three kinds of cognitive theories for using multimedia learning, especially audio visual media, namely 1) Dual channel assumption (one can 
only learn from one side only, either audio or video only), 2) Limited capacity assumption (someone who are able to learn audio-visual but have limited cognitive capacity), 3) Active learning assumption (able to receive audio-visual information simultaneously without experiencing problems) [9].

\subsection{Visual Media and Therapeutical Functions}

Visual media are media whose exposure is received through the sense of sight. The variety of visual media, when classified from its physical type, includes print media (such as magazines, books, posters), electronic media (such as television, film, animation), and interactive media (such as games and interactive CDs). Besides being classified according to the types of problems, therapy using visual media is also classifiedaccording to age. Thus handling the same case but for different ages of people will also involve different visual presentations. It is logical if the presentation or description of an object is distinguished in terms of how itsvisualization, for example,the way to present media visualization for children will be different from the ones for adolescents or adults. Although there are also cases in which a person is physically mature, but their mental development is still in the state of children.

The forms of therapiesusing visual media include painting and drawing, writing, film, visual novels, comics, interactive media, and so on. The therapeutic activities carried out are intended to rebalance the function between the ability to think that involves the work of the brain and to feel that involves the role of emotions during the process of interacting between individuals and visual media (both the process of creating or enjoying work displayed through visual media), as well as psychomotor which involves working muscles with the brain.

Art therapy activities for ordinary people may only look like class activities or art courses in general, but there areactually some differences. Activities in art therapy are more concerned with the creative process rather than the ability of individuals to produce real artwork [10]. This is because the goal of art therapy is not to produce aesthetic works like artists, but to help sufferers of psychological disorders to improvetheir conditions.

\subsection{Media Visual Media and Resillience}

One disorder in psychology is PTSD or commonly called psychological trauma. This condition is caused by high levels of stress or pressure. This stress level is certainly caused by problems faced in the past where a sufferer considers the problem very difficult to deal with. The pressure of a problem can be either a direct pressure or an accumulation of various or a series of problems.

To prevent trauma from causing fatal result, an effort that can be pursued to relieve pressure and harmonize the mind is developing resilience. Resilience is often referred to as ego-resilience or trait in another term [11]. Ego-resilience is a high and flexible adaptability in facing internal and external pressure, whereas trait is the hidden capacity of individuals which can arise to overcome psychological trauma and protect them. Trait can be developed either simultaneously or gradually.

A sufferer may try to recover from his trauma with his own awareness or with stimulants from others (for example psychiatrists, psychology therapists, family, close friends, or others) so that he has a sense to flow and make peace with the pressure,like a surfer who reconciles with the giant waves so that he is able to show his surfing performance well, and not against the waves so that they will roll him up and become bad news to convey.

As mentioned earlier regarding the variety of visual media, the samples or case studies of these media are comics and illustrations, films, and interactive animations. Illustration or comic media are visual media that engage trauma sufferers to interact with static images that have narratives in them. Film media engages sufferers who watch to follow its narrative side. Film media combines visual and audio products, whereas interactive animation media is more focused on the 
psychomotoric area, although its exposure may also inlcude development in terms of cognitive development.

Illustration is a way to visualize one's ideas. This means that analysisusing illustrations is like seeing into a mirror of someone's mind. The action of creating illustrations not only produces drawings or paintings but also shows an image of a trauma sufferer. The Rorschach test that uses ink files to analyze a person may reveal the personality or the other side of a patient that is not known beforehand.

Comic are one of the most popular media, but it is in fact not a trivial object. In comics there are visual and narrative elements that are exposed simultaneously. By presenting certain messages through these elements, comics can become an effective medium that explore various genres. Comics that are composed of narrative and visual elementswill indirectly lead tothe condition of proclamation, because people willbasically realizethat comics are entertainment media. But the thing sometimes is not realized is the message presentedin comics. Some comics contain certain content that might be recommended to be used as a medium for therapy for trauma caused by tragic event, for example Maus comics by Art Spiegelman, Tintin "Lotus Bleu" by Herge, and the thechinesewhispers.com comic website by Rani P. Collaborations.

Maus' comic tells about the atrocities of Nazi cruelty experienced by prisoners in concentration camps. Maus comicis presented as a visual fable thatreplaces the Nazis with cat visuals and prisoners with mouse visuals. The visual use of animals is intended to reduce the emotions of the readers who either directly or indirectly have memories of the event.

Tintin comic, a work by Belgian comic artist with the nickname Herge, always presents stories of adventures around the world, and the creation of the work is always preceded by research conducted by special teams [12]. Thus, the background of the narration and the visual elements can be based on a true story. One of the highlights is the edition of "Lotus Bleu" or "Blue Lotus" which tells about the condition of the Nanking Rape event. A sad story from the long history of the People's Republic of China, where there was a large massacre done by the Japanese imperial army against Chinese citizens in the Nanking region. This event is still very traumatic for the Chinese people today. But when the event is presented through comics, a different form of feeling arises, the acceptance of a traumatic event through the entrance of entertainment.

In line with this, a comic in website format, thechinesewhispers.com, discusses the 1998 tragedy in Jakarta [13]. The comic describes a variety of events experienced by the Chineseethnic who they experienced a series of dark tragedy at that time. But the creator has a brilliant idea of adopting a website system to display the comic. Along with the changing times, comic media is also experiencing development, namely the presence of digital platforms, so that comics can be accessed using soft files, such as based on websites, webtoon, or e-gallery [14]. This presentation may be conducted to obtain feedback from those who have the same fate or period in various parts of the world.

One of the media that is similar to comics is film. A filmpresents moving images and audio. There are so many movie titles that feature adaptation stories from real events that are tragedy. The tragedy may either be experienced by an individual orby a nation or ethnic group that can be classified as human tragedy, such as the Rwanda Hotel. Films sometimes also feature psychological cases that can become insights for ordinary people, such as Shutter Island, Stoneheart Asylum, Beautiful Mind, and many more.

Animations that are often used for psychological therapy are the interactive ones. Apart from cognitive approaches, interactive animation also usespsychomotoric approach, making it more suitable for sufferers who are not only experiencing disorders of the brain or memory, but also thosewho experience impaired motion function. In addition, therapy using this type of media can stimulate people to be more active in acting and interacting personally, although an assistance or guidance must indeed be provided. 


\section{CONCLUSION}

In the realm of psychology there are many categories and symptoms of psychological disorders. Some of the symptoms of psychological disorder can be reduced or even cured through therapy using visual media. Likewise with PTSD cases or trauma from past events, some of them can be treated by displaying or presenting visual media to the sufferer to boost their hope and comfort to recover or reduce theirtrauma. Resilience is one of the efforts developed to make peace with oneself on a problem that causes stress and to protect themselves from these pressures. To improve resilience, media to motivate trauma sufferersare needed, one of which is by using visual media with many choices both in terms of physical varieties and contents that can be adjusted by considering certain aspects. Some examples of the visual media used for psychological therapies are illustrations (drawings and paintings), comics, films, and interactive animations.

\section{REFERENCES}

[1]. Tim RedaksiKamusBahasa Indonesia. KamusBahasa Indonesia. Jakarta: PusatBahasaDepartemenPendidikanNasional. 2008.

[2]. J. T. Cacioppo and L. A. Freberg. Discovering Psychology: The Science of Mind. Belmont: Wadsworth Cengage Learning. 2013.

[3]. Jo Hemming. How Psychology Works. New York: DK Publishing. 2018.

[4]. U. Rohmah.ResiliensidanSabarSebagaiResponPertahananPsikologidalamMenghadapi Post-Traumatic. IlmuDakwah: Academic Journal for Homiletic Studies, Vol. 6, No. 2, pp. 312-330. 2012.

[5]. S. McCloud. MemahamiKomik. Jakarta: KepustakaanPopulerGramedia. 2001.

[6]. Sumartono. MetodologiPenelitianKualitatifSeniRupa\&Desain. Jakarta: PusatStudiRekaRancang Visual danLingkunganUniversitasTrisakti. 2017.

[7]. K. H. Kripendorf. Content Analysis: An Introduction to Its Methodology. California: Sage Publication, 2004.

[8]. L. Manovich. The Language of New Media. USA: MIT Press. 2001.

[9]. R. A. Firmansyah and A. T. Wrastari. "PengaruhPenggunaanFilmSebagai Media BelajarTerhadapPencapaian Higher Order Thingking Skill padaMahasiswaPsikologiUNAIR". JurnalPsikologiKlinisdanKesehatan Mental, Vol.3, No. 1, pp. 40-47. 2014

[10]. S. R. Anoviyanti. "TerapiSeniMelaluiMelukispadaPasienSkizofreniadanKetergantunganNarkoba". Jurnal Visual Art \&DesainITB, Vol. 2, No. 1, pp. 72-84. 2008.

[11]. Z. Uyun. "ResiliensiDalamPendidikanKarakter" Prosiding Seminar NasionalPsikologiIslami. Pp. 200208. 2012.

[12]. D. T. Ardianto, D. Susanto, and S. Mataram. "Onomatopoeia SebagaiPembukaanSignifikasiTeksdalamKomikTintinPetualanganTintinPenerbangan 714 ke Sidney versiTerjemahanBahasa Indonesia”. Mudra JurnalSeniBudaya. Vol. 33, No. 2. Pp. 223-231. 2018.

[13]. thechinesewhispers.com

[14]. S. Mataram and D. T. Ardianto. “ Digital Comic Platform Mapping for Improving The Creative Industry Potential". Proceeding 3rd International Conference on Creative Media, Design and Technology (REKA 2018). Vol. 207. 2018 